\begin{tabular}{|l|c|c|c|cc|l|}
\hline \multirow{2}{*}{2} & J O P Y & 558 & \multirow{2}{*}{$\mathbf{B}$} & Dispatch: $30.12 .08 \quad$ Journal: JOPY & CE: Sukanya \\
\cline { 2 - 5 } \cline { 5 - 7 } & Journal Name & Manuscript No. & & Author Received: $\quad$ No. of pages: 39 & PE: Suseela/Mini \\
\hline
\end{tabular}

\title{
Maltreated Children's Representations of Mother and an Additional Caregiver: A Longitudinal Study
}

\author{
Shany Manashko, ${ }^{1}$ Avi Besser, ${ }^{2}$ and Beatriz Priel ${ }^{1}$ \\ ${ }^{1}$ Ben-Gurion University of the Negev \\ ${ }^{2}$ Sapir Academic College
}

In the current longitudinal investigation, we explored the continuity of and changes in the mental representations of the mother and an additional caregiver among forty-five 9- to 11-year-old children who had been severely maltreated and subsequently placed in long-term residential care, as well as the relationships between the content and structure of these representations and teacher's assessments of the child's externalizing and internalizing symptoms. At Time 1, a nonmaltreated comparison group was assessed concomitantly. Compared to nonmaltreated children, maltreated children scored higher for externalizing and internalizing symptoms and their maternal representations were found to be significantly less benevolent and integrated and more punitive. In addition, among the maltreated children, the additional caregiver representations were found to be more benevolent and integrated, and less punitive, than the maternal representations. After 30 months, the maltreated children's levels of externalizing and internalizing symptoms diminished and their maternal representations become more benevolent and less punitive, and the additional caregiver representations became less benevolent. Moreover, the Benevolence of the additional caregiver representation was found to predict these children's changes in externalizing symptoms beyond the effects of their symptomatology and its associations with the Benevolence of these representations at Time 1 .

We are very grateful to the staff and children of the S.O.S Children's Village "Neradim" for their invaluable help and cooperation in making this research possible.

We acknowledge a grant for partial support of this work from the Research Advisory Board of the International Psychoanalytical Association. We acknowledge the support of the Israeli Association for Research and Education Funds.

We thank the anonymous reviewers for their constructive suggestions.

Correspondence concerning this article should be addressed to Beatriz Priel, Ph.D., Department of Psychology, Ben-Gurion University, Beer-Sheva 84105, Israel. E-mail: bpriel@bgumail.bgu.ac.il.

Journal of Personality 77:2, April 2009

(C) 2009, Copyright the Authors

Journal compilation (C) 2009, Wiley Periodicals, Inc.

DOI: $10.1111 / \mathrm{j} .1467-6494.2008 .00558 . x$ 
Attachment, object relations, and social-cognitive theories converge in the assumption that mental representations of early relationships affect children's behavior and their subsequent close relationships (Baldwin, 1992; Blatt \& Lerner, 1983; Bowlby, 1969, 1973, 1980; Bretherton \& Munholland, 1999; Main, Kaplan, \& Cassidy, 1985; Sandler \& Rosenblatt, 1962; Westen, 1991). According to these theoretical perspectives, experiences in relationships with significant others are organized and modeled into internal schemas or representations; these schemas are conceptualized as developmental structures that guide subsequent interpersonal perception and functioning. Attachment research has shown that secure internal working models of early relationships are significant predictors of adaptive functioning, whereas insecure models are associated with symptomatic behavior (Fonagy \& Target, 1997; Hesse, 1999). Similar results have been obtained in studies of children's narrative representations of significant caregivers (Besser \& Blatt, 2007; Segal, Westen, Lohr, Silk, \& Cohen, 1992; Shields, Ryan, \& Cicchetti, 2001; Waniel, Besser, \& Priel, 2006). Greenberg (1999) described two possible mechanisms that may explain the association between less than optimal internal representations and maladaptive behavior: Nonoptimal internal models may lead to maladaptive patterns of behavior or, alternatively, negative representations may increase the risk of the appearance of other risk factors. Because deviant relationship patterns and severe additional risk factors are usually present concomitantly, we may assume that both possibilities may converge. For instance, the atypical parental representations that reflect the maltreated child's reality may lead to maladaptive relationship patterns and increase the effects of ecological risk factors, as well.

The extremely negative interpersonal experiences that characterize child maltreatment have been assumed to produce predominantly negative mental representations of caregivers. An impressive array of studies has documented the negative characteristics of maltreated children's parental representations and their association with increased levels of symptomatology (Macfie et al., 1999; Manly, Kim, Rogosch, \& Cicchetti, 2001; McCrone, Egeland, Kalkoske, \& Carlson, 1994; Toth, Cicchetti, \& Kim, 2002; Toth, Cicchetti, Macfie, \& Emde, 1997; Toth, Cicchetti, Macfie, Maughan, \& Venmeenen, 2000). In addition, the mental representations of maltreated children have also been found to be more concrete and less complex than 
the mental representations of nonmaltreated children (Shields et al., 2001; Westen, 1991).

The long-term effects of parental representations have been interpreted as being related to the active role of children in structuring their own environments and experiences, as well as to the tendency to interpret new experiences congruently with earlier ones (Sroufe, Carlson, Levy, \& Egeland, 1999). This continuity has been seen as sometimes distorting perceptions of newer relationships, and these distortions have been explained as schematic sensitivity (Baldwin, 1992) or defensive strategies (Blatt, 1995; Bretherton \& Munholland, 1999).

Although there is strong evidence of long-term continuity of representational patterns, a transactional perspective on child development suggests that significantly different environmental conditions might promote the construction of additional, different caregiver representations (Sameroff, 1995). That is, changes in the child's proximal ecology (Cicchetti \& Toth, 2002) may consequently moderate maltreatment sequelae. Research findings may strengthen this assumption. In a survey of studies of resilience among children raised in adverse environments, E. E. Werner (2000) listed the affect and encouragement of additional caregivers among the major protective factors. Moreover, secure attachment within a network of attachments has been found to positively affect children's adjustment, suggesting better outcomes if different attachment representations are integrated (Fonagy \& Target, 1997). In a longitudinal study, Egeland, Jacobovitz, and Sroufe (1988) showed that the women who had been maltreated as children-but did not abuse their own children - were those who had experienced a close relationship in their childhood with a positive figure (teacher, neighbor, etc.) or therapy as an adult.

However, the question of the continuity-discontinuity of internal representations of main caregivers is still open, and the controversy has been reiterated in recent literature (Weinfield, Whaley, \& Egeland, 2004). Studies have shown that maltreated children tend to perceive new relationships through the prism of their parental representations (Howes \& Segal, 1993; Lynch \& Cicchetti, 1991; McCrone et al., 1994; Toth \& Cicchetti, 1996). These findings have been interpreted as resulting from a hierarchical organization of representations, in which subsequent representations are assumed to be constructed following the model of former ones. Accordingly, a 
relative similarity between the representation of the main caregiver and subsequent representations of relationships is expected (Bretherton, 1985). However, it is plausible to assume that the relative stability of relationship patterns found among maltreated children might reflect not only the constancy of individual differences but also the continuity of environmental conditions. Moreover, children's behavior might be maladaptive because it recreates and perpetuates the existing environment (Weinfield, Sroufe, \& Egeland, 2000).

A central dilemma in the treatment of children at severe risk is the question of whether to remove the child at risk from the home. The implications of alternative placement for child, family, and society are very serious. These decisions are especially difficult, and evaluations of the results of the removal of these children from their homes are, at the least, confusing (Chapman, Wall, \& Barth, 2004; Davidson-Arad, 2005; Milan \& Pinderhughes, 2000; Thompson, 2000). In general, the findings of research on the specific experiences of maltreated children in long-term residential care clearly underscore the importance of an additional positive caregiving figure for children's adjustment (Dozier, Albus, Fisher, \& Sepulveda, 2002; Rosenfield et al., 1997; Rutter, 1989). In spite of the history of children's harsh relationships and the distancing of their primary caregiver, an additional caregiver's attunement, sensitivity, and nurturing behavior have been found to be helpful for the development of their regulatory capacities. Moreover, positive changes in the attachment behavioral system seem to frequently accompany the provision of a more adequate caregiving environment (Dozier et al., 2002). Howes and Segal (1993) observed that almost half of a sample of toddlers, removed from their homes because of maternal maltreatment were able to form secure relationships with their new caregivers. In addition, child-new caregiver relationships have been found to have the potential to reduce the intergenerational transmission of maltreatment (Milan \& Pinderhughes, 2000). This line of research suggests that the possibility of creating a positive bond with an additional caregiver in a new environment may lead to the moderation of the effects of a history of maltreatment on children's adjustment and well-being.

Although developmental research provides important evidence of the associations between maltreated children's internal representations and adjustment in general, and the possibility of the 
formation of more benign relationships with an additional caregiver in particular, less is known about how different models of relationships change with time or about the predictive power of different coexistent internal models of relationships among maltreated children removed from their homes.

\section{The Present Study}

In the present study, we intended to compare maternal and additional caregiver representations and their effects on the symptomatic behavior of maltreated children in long-term residential care. Following a transactional developmental perspective (Sameroff, 1995) and the conceptualization of children's representations of their caregivers as developing constructs (Thompson, 2004), we assumed that children exposed to a new environment and sensitive caregiving may construct positive representations of a new additional caregiver. Moreover, in the present study we assumed that these children's representations of their mother and of their additional caregiver will predict the children's behavioral problems across time.

This study centers on changes in the structure and content of the internal representations of mother and additional caregiver among maltreated school-age children placed in long-term residential care. To this effect, we used a semistructured interview technique, the Object Relations Inventory (ORI; Blatt, Chevron, Quinlan, Schaffer, $\&$ Wein, 1992). The ORI narratives provide an account of the caregiver or parental figure as experienced by the child. A major aspect of this technique is the differentiation made between content and structural aspects of mental representations, a procedure that has also been followed by other researchers of child development (see Shields et al., 2001). The content dimension is assumed to capture children's caretaking experiences, the affective tone of parent-child relationships, and the child's expectations. Content categories were thought to involve references to parental support, affection, and involvement (Benevolence factor) as well as to parental restrictions, critical, and punitive stance (Punitiveness factor). The structural dimension is assumed to reflect the representation's basic cognitive organizing principles within the perspectives of Piaget $(1955,1962)$ and H. Werner (1948), indicating the level of processing of the information the child has gathered about significant others. This is a 
core distinction between the phenomenological characteristics of the described figure and the organizational and regulatory principles involved in these representations. Previous research findings corroborate the association between the content and structure of parental representations and symptomatic behavior among school-age children and preadolescents (Besser \& Blatt, 2007; Priel, 2005; Segal, Westen, Lohr, Silk, \& Cohen, 1992; Shields et al., 2001; Waniel et al., 2006).

This paper describes a longitudinal study with two waves of data collection designed to follow both the changes of representations and their effects on symptomatology over time. Based on previous research, we expected that at Time 1 maltreated children would exhibit more negative representations and increased internalizing and externalizing symptomology than nonmaltreated children. Among maltreated children, the representations of the additional caregiver were expected to be more positive than maternal representations. We also assumed that the structure of both maternal and caregiver representations would improve over time. Finally, we expected that the maltreated children's maternal and additional caregiver representations would correlate with symptomatology at Time 1 and predict the levels of externalizing and internalizing symptoms at Time 2.

The following specific hypotheses were tested:

Hypothesis 1. Compared to nonmaltreated children's representations, the maternal representations of maltreated children were expected to present higher levels of the Punitiveness factor and lower levels of both the conceptual level variable and the Benevolence factor.

Hypothesis 2. Within the sample of maltreated children at both measurement times, we expected that the representations of the mother would score higher for the Punitiveness factor and lower for the Benevolence factor than the representations of the additional caregiver.

Hypothesis 3. In the two samples investigated we expected that the dimensions of the representations at Time 1 will be correlated with children's concurrent levels of symptoms.

Hypothesis 4. The dimensions of the maltreated children's representations of their birth mother and additional caregiver at Time 1 were assumed to predict their levels of symptomatology at Time 2 (see Figure 1 for this crossed-lagged model). 


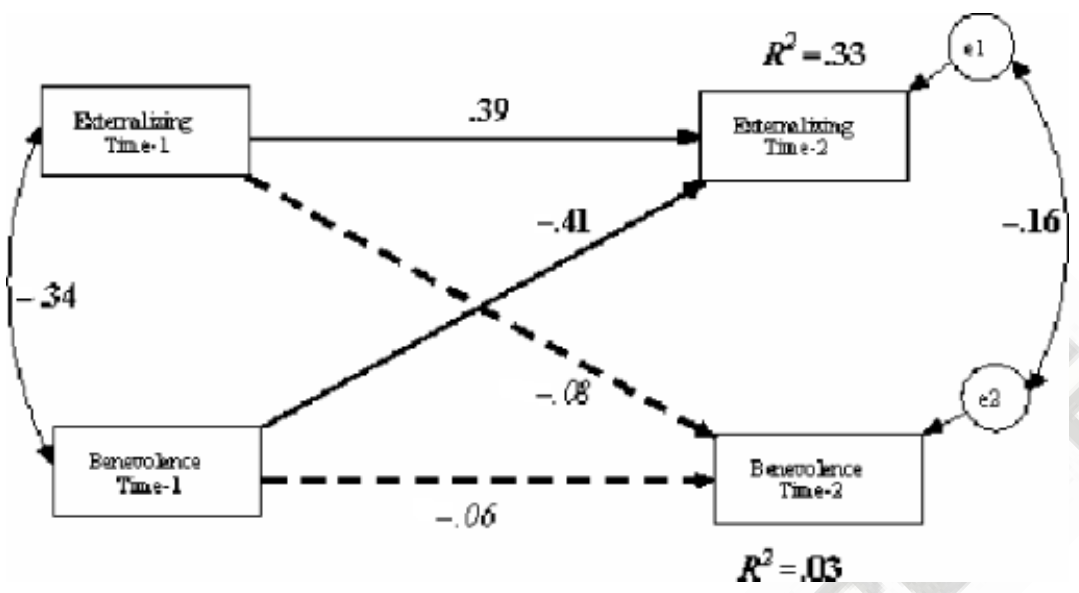

Figure 1

The Crossed-Lagged Model. Rectangles indicate measured variables. Small circles reflect residuals (e); bold numbers above or near endogenous variables represent the amount of variance explained $\left(R^{2}\right)$. Unidirectional arrows depict hypothesized directional, or "causal," links/associations. Standardized maximum likelihood parameters are used. Bold estimates are statistically significant. The dotted paths indicate nonsignificant, "causal" links/associations.

\section{METHOD}

\section{Participants}

Participants were 45 children ( 23 girls and 22 boys) who had been removed from their homes by court order because of maltreatment and referred to a long-term residential care by social service agencies and a matched comparison group of 45 nonmaltreated children ( 23 girls and 22 boys) from a similar socioeconomic background. The socioeconomic status of the children was calculated using the Israel Central Statistical Bureau Index (ratio between the number of persons living in the same household and the number of rooms in the home). The age of the participants in both groups ranged from 9 to 11 years, with maltreated children averaging 9 years 4 months $(S D=0.90)$. The average age of the nonmaltreated children was 9 years 6 months $(S D=0.61)$. Additional caregivers were aged $41-57$ (mean $=51.17, S D=4.86)$ and had a mean 12.5 years $(S D=2.5)$ of formal education. Six of the caregivers were born in Eastern Europe, three in Israel, and one in Asia.

The maltreated children were approached in an institution that provides a substitute home environment for children who have been removed 
from their homes by court order because of maltreatment. This institution contains 10 households. Each household has 7 to 9 children of varying ages who function as siblings and a permanent female caregiver who lives together with the children. It is important to note here that the additional caregiver was in all cases the same person at Time 1 and Time 2.

The soundness of care in the Institution is closely monitored by the Social Work Service of the Israeli Ministry of Welfare. All of the children maintain almost daily telephone connection with their parents, and this connection is encouraged by their caregivers. In addition, children pay monthly visits to their homes (except in cases in which the court temporarily forbids visits). Children usually remain in institutional care until they are 18 years old. The nonmaltreated children were recruited from a public elementary school that serves a population with a low socioeconomic level in the same southern district as part of a larger project on school-aged children's socioemotional development. All of the children, maltreated and nonmaltreated, attended regular schools.

\section{Procedure}

Two waves of data collection took place. Time 1 data were collected 18 to 21 months after the children's placement in residential treatment, assuming that after a year and a half most children would have established a significant bond with the additional caregiver and that the initial turmoil of leaving home and adapting to a new environment would have been surmounted, at least to some extent. At Time 1, we also assessed a comparison group of nonmaltreated children from a similar socioeconomic background. This design allowed us to compare the maternal representations of maltreated and nonmaltreated children. At Time 1, we explored the differences between mother and additional caregiver representations as well as the associations between mental representations and symptomatology.

We assessed the maltreated children a second time (Time 2) 30 months after Time 1 in order to study any changes in maternal and caregiver representations over time. We also wanted to examine the power of maternal and caregiver representations as assessed at Time 1 to predict symptomatology 30 months later, beyond the effects of the symptomatology assessed at Time 1.

Parents, teachers, caregivers, and children were asked to take part in a study of children's behavior, thoughts, and feelings about significant others. All of the maltreated children's families and $88 \%$ of the nonmaltreated children's families approached consented to participation in the study. Parental consent was obtained before checking any records or interviewing participants. Participants in the comparison ("nonmaltreated") 
group were excluded from this study if the local social services knew they were being maltreated. All the children were interviewed individually in their school setting and were assured that their anonymity would be maintained and that their responses would be used for research purposes only. The Teacher Report Forms (TRF; Achenbach, 1991) were completed by the child's homeroom teacher, that is, the teacher who is responsible for the class and has the closest personal contact with the individual children. Surveyed teachers had been acquainted with the children for periods of 6 months or longer.

After obtaining the consent of the Institution and the Ministry of Welfare, we used the social services records for descriptions of specific incidents of maltreatment in order to determine the types of abuse to which the children had been exposed. These incidents were then classified according to maltreatment subtype (physical abuse, neglect, and emotional abuse) and the age of onset of maltreatment (infancy, preschool, or school age). Two independent coders who had no knowledge of or contact with the child and his or her family assessed the presence or absence of emotional abuse, neglect, and physical abuse. Because the majority of children had experienced more than one type of maltreatment, subtype classification were made based on the hierarchical system proposed by Barnett, Manly, and Cicchetti (1993): Children who had experienced only emotional abused were classified as emotionally abused, those who had experienced neglect with or without emotional abuse were classified as neglected, and those who had experienced physical abuse with or without neglect and/or with or without emotional abuse were classified as physically abused. For each subtype, interrater agreement-weighted kappa statistics were calculated to account for variability in the maltreatment coding. We obtained kappa values of .96 for physical abuse, .74 for emotional abuse, and .84 for neglect.

Of the 45 maltreated children in our sample, $26.7 \%(n=12)$ were classified as physically abused, $53.3 \%(n=24)$ as neglected, and $20 \%(n=9)$ as emotionally abused. As mentioned before and in congruence with the literature (Cicchetti \& Rizley, 1981), the majority of the children in the maltreatment sample had experienced more than one type of maltreatment: $27 \%(n=12)$ had experienced only one subtype of maltreatment, $46 \%(n=21)$ had experienced two subtypes, and 27\% ( $n=12)$ had experienced three subtypes of maltreatment. In all cases, the mother was the primary but not necessarily the only perpetrator and all of the children had been exposed to severe maltreatment as defined by the Social Work Service of the Israeli Ministry of Welfare; severe maltreatment justifies removing the child from the parents' custody.

Regarding the age of onset of maltreatment, for $42.2 \%$ of the children in our sample $(n=19)$, maltreatment began before the age of 3. For 
$28.9 \%$ of the children $(n=13)$, maltreatment began during the preschool years (3-5 years). For the remainder of the sample, in $28.9 \%(n=13)$ of the cases, maltreatment began during the school-age years (6-11 years). In all cases, maltreatment continued until the children were removed from their homes and placed in long-term residential care. It is important to note here that none of the maltreated children in our sample, including those exposed to physical abuse, were reported to have been exposed to sexual abuse.

After creating a comfortable atmosphere and rapport and assuring anonymity, participants in the nonmaltreated group were asked to tell the interviewer about their mothers, and the maltreated children were asked to tell the interviewer about their mothers and additional caregivers.

The order of collecting mother and additional caregiver narratives among maltreated children was randomized, and no narrative immediately followed another. Children's descriptions of their mothers and additional caregivers were recorded and transcribed verbatim. These transcripts were then coded. The interviewer encouraged children with nondirective probes; additional questions were asked only when the interviewer needed to make sure he or she understood what the child meant by a specific expression or phrase. The answers to these questions were taken into account only as clarifications of the meaning of the child's narrative. Verbal fluency was measured by the mean number of words included in the spontaneous description.

\section{Measures}

Assessment of maternal and additional caregiver representations. We evaluated children's representations of their mothers using the Children's Object Representation Inventory (CORI; see Waniel et al., 2006). This measure is an adaptation of the ORI, a procedure devised for the evaluation of adult and adolescent representations of significant others (Blatt et al., 1992). The adaptation of the ORI procedure for use with children has been found to have adequate reliability and validity among populations of children (Avery \& Ryan, 1988; Besser \& Blatt, 2007; Diamond et al., 2005; Priel, 2005; Priel, Besser, \& Kantor, 2000; Priel, Myodovnick, \& Rivlin-Beniaminy, 1995; Waniel et al., 2006) as well as cross-culturally (for a review, see Priel, 2005). The CORI system allows for the assessment of and comparison between maternal and additional caregiving figures.

The coding procedure for the CORI included seven qualitative or content categories and a structural scale (for a detailed description, see Waniel et al., 2006). The content categories were rated on a 7-point scale. The seven content scales have been shown to converge into two factors defined as Punitive and Benevolent. The Benevolent factor consists of the 
following categories: affectionate, cold-warm, constructive involvement, nurturing, weak-strong, and malevolent-benevolent. This factor addresses aspects related to the degree of benevolence attributed to the caregiver figure, ranging from descriptions of an uninvolved and uncaring maternal figure to a warm and benign one. The remaining two categories, judgmental and punitive, which combine into the Punitive factor, address the degree to which the caregiver figure is experienced as threatening and disapproving, ranging from descriptions of a nonpunitive and accepting maternal figure to a punishing and highly critical one. Scores for each of these factors were obtained by averaging the ratings for each of the content categories that loaded significantly on each factor. When a child did not mention one of the categories, he or she was assigned a score for the lacking category. The assigned score was equivalent to the mean score he or she had obtained for the other scales of the factor (see the Appendix for examples of examples of coding categories of maternal and additional caregiver representations.

Whereas the content of the description can be used for an assessment of its qualitative aspects, the conceptual level of the representation constitutes a major developmental dimension of children's representations of their parent or additional caregiver. Based on the cognitive developmental stages of H. Werner and Kaplan (1963), the CORI coding procedure assumes that the development of conceptual or symbolic representations is achieved through a process of gradual differentiation and integration. Earlier forms of representation are based primarily on sensations and actions related to need gratification, intermediate levels of representation are based on specific perceptual features, and higher forms of representation become well differentiated and symbolic or conceptual. These levels are congruent with Bruner's (1964) and Horowitz's (1972) conceptualizations of inactive, imagistic, and lexical modes of representation. The conceptual level of the representation was coded on a 9-point scale, including five main levels $(1,3,5,7$, and 9 , respectively) and four intermediate levels (scores 2, 4, 6, and 8) that were used for narratives that fell in between these levels. Scale points were as follows: SensorimotorPreoperational Level (1): Persons are described primarily in terms of the gratification or frustration they provide. There is little sense that others exist as entities separate and independent of their direct effect on the subject's pleasure or pain. Concrete-Perceptual Level (3): Persons are described primarily in concrete, literal terms, usually on the basis of physical attributes and features. Emphasis is placed on external physical characteristics and appearance. Iconic Levels (5-7): (a) External-Iconic Level (5): Persons are described primarily in terms of manifest activities and functions. (b) Internal-Iconic Level (7): Persons are described primarily in terms of their thoughts, feelings, and values, rather than their physical 
characteristics or activities. The description primarily involves internal psychological dimensions. Conceptual Level (9): Using a range of levels, the description integrates external appearances and activities (behavior) with internal dimensions (feelings, thoughts, and values). Apparent contradictions are resolved in an integrated, complex, coherent synthesis.

Interviewers and coders were recruited and trained especially for this project. Interviewers were randomly assigned to children. Two independent, trained coders rated all maternal and additional caregiver representations. Children's narratives were coded for each indicator separately, coders being blind to the child's group (maltreated or nonmaltreated) and to the expected factor structure as well as to the fact that we had two measures taken at different times. The interrater intraclass correlation reliability coefficients (Shrout \& Fleiss, 1979) obtained for each of the seven qualitative or content categories in the present study ranged from .78 to .90 . The interrater reliability coefficients for the coding of each factor of the maternal and additional caregiver representations were $r=.83$ and $r=.89$ for Benevolence, $r=.81$ and $r=.90$ for Punitiveness, and $r=.85$ and $r=.87$ for conceptual level, for the maternal and additional caregiver, respectively.

Child symptomatology. We assessed children's symptomatology by means of teachers' reports of behavioral and emotional problems using the Externalizing and Internalizing factors of the TRF of the Child Behavior Checklist (Achenbach, 1991), a widely used teacher-report questionnaire designed to assess behavioral problems in children between 5 and 18 years of age. The Externalizing Problems factor of the TRF includes the presence of delinquent and aggressive behavior. The Internalizing Problems factor relates to withdrawal, anxiety or depression, and somatic complaints. The TRF has high concurrent validity (above .80) and is associated significantly with the Diagnostic and Statistical Manual of Mental Disorders criteria (Achenbach, 1991; American Psychiatric Association, 1994). In the present study, we obtained internal consistency coefficient Cronbach's scores of .73 and .64 for Externalizing and Internalizing symptoms, respectively.

\section{RESULTS}

\section{Overview of Results}

The findings are presented in three main sections. First, we discuss potential differences between maltreated and nonmaltreated children 
in relation to demographic variables. The following demographic variables were considered: child's age and gender, mother's and father's ages and years of formal education, child's birth order, family size and socioeconomic status, and verbal fluency. Within the maltreated children group, we also explored the differences among the foster homes within the Institution (i.e., repeated measure of children within the same home), as well as among subtypes of maltreatment and different ages of onset of maltreatment. Although there were no a priori hypotheses regarding these variables, they could affect the findings obtained. Therefore, we explored whether any of these variables were associated with the main study variables in order to ensure that any covariance could be accounted for in subsequent analyses of our main hypotheses.

Next, we present a comparison of the symptoms and maternal representations of the two groups of children (maltreated vs. nonmaltreated) at Time 1 and the results of our study of the associations between symptoms and dimensions of mental representations. Within the group of maltreated children, we also compared representations of mothers with those of additional caregivers.

Finally, we discuss the findings of our analysis of changes in the maltreated children's symptoms and their representations of their mothers and additional caregivers over time as well as the associations between these children's symptoms and their representations of their mothers and additional caregiver over time.

\section{Preliminary Analysis}

The main demographic variables for maltreated and nonmaltreated children are presented in Table 1 . The results of analyses of variance (ANOVA) indicated that the two groups did not differ significantly in terms of the examined demographic variables: child's age, mother's and father's ages and years of formal education, child's birth order, family size, and socioeconomic status. The sex ratios of the two groups were also not significantly different from one another. After a full Bonferroni correction was applied, a significant difference was found between the verbal fluency of the narratives of the two groups, $F(1,88)=12.49, p<.001$ (for means, standard deviations, and $F$ values, see Table 1 ). Analyses of the associations of the demographic variables and verbal fluency with the study's dependent variables (representations and symptomology scores) indicated sig- 
Table 1

Demographic Characteristics of the Sample

\begin{tabular}{|c|c|c|c|c|c|}
\hline \multirow[b]{2}{*}{ Variable } & \multicolumn{2}{|c|}{$\begin{array}{l}\text { Maltreated } \\
\text { children }\end{array}$} & \multicolumn{2}{|c|}{$\begin{array}{l}\text { Nonmaltreated } \\
\text { children }\end{array}$} & \multirow[b]{2}{*}{$F(1,88)$} \\
\hline & $M$ & $S D$ & $M$ & $S D$ & \\
\hline Father's age & 41.00 & 1.14 & 40.89 & 1.16 & $0.18, n s$ \\
\hline $\begin{array}{l}\text { Father's years } \\
\text { of education }\end{array}$ & 11.89 & 1.30 & 12.46 & 1.73 & $0.43, n s$ \\
\hline Mother's age & 36.52 & 0.83 & 37.02 & 0.88 & $0.17, n s$ \\
\hline $\begin{array}{l}\text { Mother's years } \\
\text { of education }\end{array}$ & 12.05 & 1.99 & 12.99 & 1.52 & $0.42, n s$ \\
\hline Child's age & 9.40 & 0.83 & 9.60 & 0.65 & $6.40, n s$ \\
\hline Family size & 3.12 & 0.22 & 2.73 & 0.20 & $1.62, n s$ \\
\hline Birth order & 2.28 & 0.20 & 2.14 & 0.27 & $0.24, n s$ \\
\hline SES & 1.04 & 0.75 & 0.91 & 0.80 & $0.35, n s$ \\
\hline Verbal fluency & 26.37 & 2.43 & 2.43 & 35.03 & $12.49 *$ \\
\hline
\end{tabular}

$* p<.05$ (two-tailed test).

nificant associations only between verbal fluency and children's maternal representation variables. Specifically, the correlations between verbal fluency and Benevolence scores were $r=.36(p<.05)$ and $r=.31(p<.05)$ for maternal and additional caregiver in the maltreated group, respectively; the correlation between verbal fluency and Benevolence was $r=.28(p<.05)$ in the nonmaltreated group. The correlations between verbal fluency and conceptual level were $r=.28(p<.04)$ and $r=.26(p<.04)$ for additional caregiver representation and maternal representations among maltreated children, respectively, and $r=.27(p<.04)$ for maternal representation among nonmaltreated children. Thus, in the subsequent analyses of maltreated versus nonmaltreated children's representation scores, the verbal fluency (i.e., length of the narratives) was covaried.

Within the sample of maltreated children, we also explored the possible associations between subtype of maltreatment and age of onset of maltreatment and the study variables. No significant associations were found. We also explored the possible effects of the different foster homes (i.e., repeated measures of children within the same home in the Institution) and the study variables. Thus children are nested within the 10 caretakers. Hieratical Linear Modeling 
analysis with caretakers and children levels revealed no significant effect for children or caretakers or for a Children $\times$ Caretakers interaction effect on study variables. Thus there is no specific household or children that are the source of the effects obtained for the maltreated sample. Even though children are nested within the 10 caretakers, these were found to be statistically independent.

\section{Analysis of Data at Time 1}

Externalizing and internalizing symptoms. To explore the effect of maltreatment status on children's externalizing and internalizing behavioral problems, ANOVAs were conducted with maltreatment status (maltreated vs. nonmaltreated) as the independent variable and symptomatology (Externalizing and Internalizing behavioral problems scores) as the dependent variables. After a full Bonferroni correction was applied, these analyses revealed that maltreated children scored higher for Externalizing, $F(1,88)=26.98, p<.0001$ $(M=29.09, S D=2.25$, and $M=12.56, S D=2.24$, for maltreated and nonmaltreated, respectively), and Internalizing behavior problems, $F(1,88)=6.29, p<.01(M=16.88, S D=1.32$, and $M=12.26$, $S D=1.03$, for maltreated and nonmaltreated, respectively).

Maternal representations. To explore the effect of maltreatment status on children's maternal representation scores, analyses of covariance were conducted with maltreatment status (maltreated vs. nonmaltreated) as the independent variable and the maternal representations' dimensions scores (Benevolence, Punitiveness, and conceptual level score) as the dependent variables. Verbal fluency was covaried. After a full Bonferroni correction was applied, univariate $F$ results indicated that, as compared to the nonmaltreated children, the maltreated participants' maternal representations scored significantly lower for conceptual level, $F(1,88)=8.78, p<.001$, and Benevolence, $F(1,88)=45.48, p<.0001$, and higher for Punitiveness, $F(1,88)=6.75$, $p<.01$ (for means and standard deviations, see Table 2).

Maternal and additional caregiver representations. To compare representations of mothers with those of additional caregivers (Benevolence and Punitiveness and conceptual level) within the maltreated group, three dependent $t$ tests were computed. After a full Bonferroni correction was applied, the results indicated that, as compared 


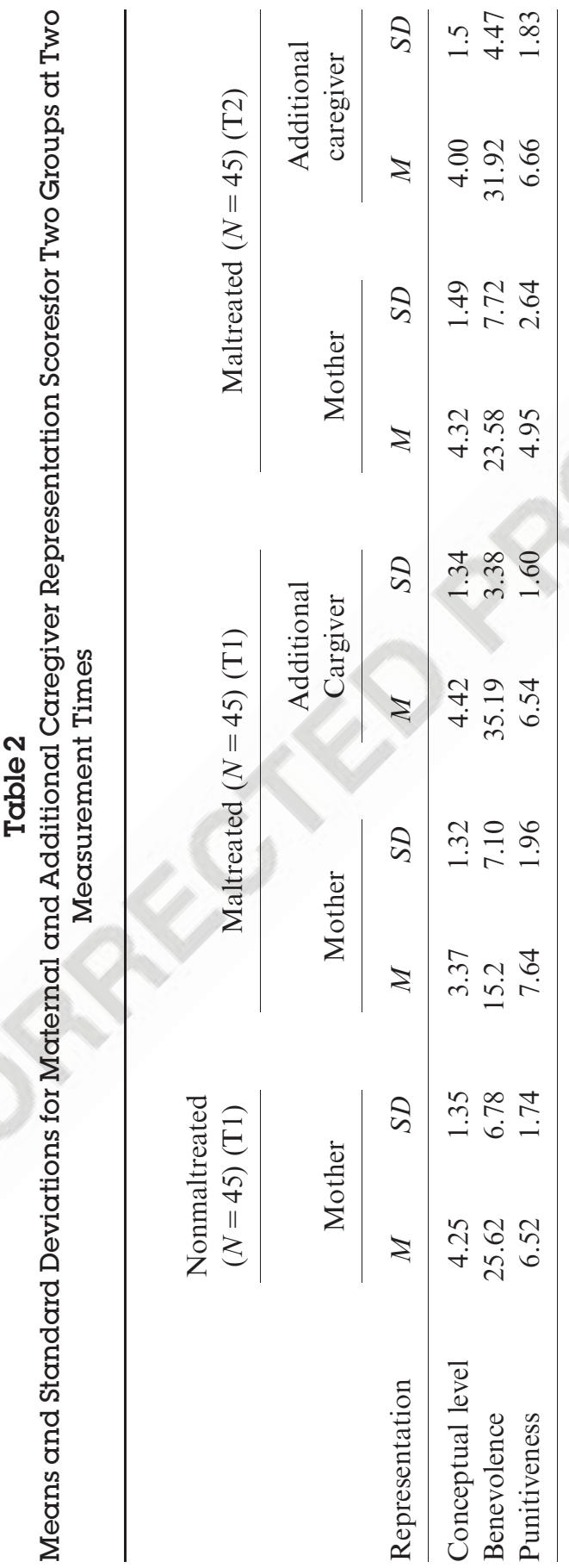


to their maternal representations, maltreated children's representations of their additional caregiver scored significantly higher in terms of conceptual level, $t(1,44)=3.56, p<.001$, and Benevolence, $t(1,44)=16.82, p<.0001$, and lower in terms of Punitiveness, $t(1,44)=-2.93, p<.001$ (for means and standard deviations, see Table 2).

Maternal and additional caregiver representations and symptoms. We first computed a full zero-order person correlation matrix among the dimensions of maternal and additional caregiver representations (Benevolence, Punitiveness, and conceptual level) and Externalizing and Internalizing behavioral problems among the maltreated children. The following correlations were the only ones found to be statistically significant.

Significant negative associations were found between the Benevolent and the Punitive factors of both the maternal representations and the additional caregiver representations $(r=-.50, p<.01$ and $r=-.54$, $p<.01$, respectively). In addition, positive correlations were found between Externalizing and Internalizing behavior problems $(r=.53$, $p<.01)$ among maltreated children. Moreover, the Benevolence factor of the additional caregiver representations was negatively associated with Externalizing behavioral problems $(r=-.34, p<.05)$. No significant associations were found between the additional caregiver representations and Internalizing behavioral problems.

A different pattern of correlations was found for the maltreated children's representations of their mothers. No correlations whatsoever were found between Externalizing and Internalizing behavioral problems and the content factors or the conceptual level of maternal representations. Moreover, nonsignificant correlations were noted between maltreated children's representations of their additional caregiver and mother (Pearson $r$ correlation coefficients between Benevolence, Punitiveness, and conceptual level of maternal and additional caregiver representations were $.05, .20$, and -.04 , respectively).

These findings seem to indicate that, among maltreated children, the Benevolence of the additional caregiver representation, but not of the maternal representation, is associated with the child's behavior. These findings do not, however, rule out the possible interaction effect by which the effect of the Benevolence of the additional caregiver representation on a child's Externalizing problems might be qualified by the level of Benevolence of that child's maternal repre- 
sentation, as previously found among the Benevolence of birth and adoptee mothers in the prediction of adoptee children's behavior (see Priel et al., 2000).

To further explore this possibility, a three-step Hierarchical Multiple Regression (HMR) analysis was performed. In the first step, maternal Benevolence was entered into the model and did not significantly contribute to the prediction of Externalizing behavioral problems $(\beta=.20, t=1.63, n s)$. In the next step, the additional caregiver Benevolence was included in the model and was found to be a significant predictor of Externalizing behavioral problems $(\beta=-.30, t=-2.16, \quad p<.03)$, adding $15 \%, F$ change $(2,48)$ $=5.31, p<.002$, to the explained variance in Externalizing symptoms, overall $F(2,48)=4.10, p<.02$. When the interaction between the Benevolence of the mother and that of the additional caregiver was added in the third step, however, it was not found to be significant $(\beta=.22, t=.14, n s)$. Thus, only the Benevolence of the additional caregiver representation is a significant predictor of Externalizing problems, and the final model explains $15 \%$ of the variance of Externalizing problems.

A full correlation matrix was also computed for the dimensions of maternal representations and children's symptomatology among nonmaltreated children. Among these correlations, the only significant ones were for the Benevolence factor of maternal representations that was negatively associated with Externalizing behavioral problems $(r=-.33, p<.05)$ and negatively associated with the Punitive factor $(r=-.31, p<.05)$. No significant correlation was found between Externalizing and Internalizing behavior problems. No significant associations were found between maternal representation dimensions and Internalizing behavioral problems. Thus, among maltreated children, the Benevolence factor of the representation of a child's additional caregiver was associated with Externalizing problems whereas among nonmaltreated children, the Benevolence factor of the representation of the mother was associated with Externalizing problems. ${ }^{1}$

1. To examine the effects of the Benevolence of the maltreated children's additional caregiver and the nonmaltreated children's maternal representations on children's Externalizing symptoms beyond group effects, we computed an HMR. In the first step, we entered the maltreatment status (maltreated vs. nonmaltreated), which made a significant contribution to the prediction of Externalizing 
To ensure that the correlations between the additional caregiver's Benevolence (as perceived by the child) and the maltreated children's Externalizing symptomatology as well as the correlations between the Benevolence scores for the maternal representations of the nonmaltreated children and the Externalizing symptomatology of those children are robust and not arbitrary, we regressed all content dimensions on the Externalizing scores within each group. Our results indicated that Benevolence is still the only correlative of Externalizing in both groups, beyond other dimensions of representations $(\beta=-.27, t=-2.0, p<.05$ and $\beta=-.29, t=-2.24, p<.03$ for maltreated and nonmaltreated children, respectively.

Summary of findings at Time 1. The main findings of the data obtained at Time 1 show that the additional caregiver representations of the maltreated children were significantly higher in terms of conceptual level and Benevolence and lower in terms of Punitiveness than their maternal representations. As shown in the preliminary analyses, these findings were not affected by subtype of abuse, age of onset of maltreatment, or differences among the foster homes (i.e., repeated measures of children within the same home). In addition, the Benevolence of the maternal representations of the nonmaltreated children and of the additional caregiver representations of the maltreated children were significantly associated with the levels of Externalizing problems reported by the teachers. Dimensions of the maltreated children's maternal representations were not associated with the additional caregiver representation dimensions or with the children's behavioral problems at Time 1.

\section{The Longitudinal Study of the Maltreated Children}

We first explored changes over time in maternal and additional caregiver representations as well as in symptomatology levels of the individual maltreated children. We then explored the association

problems $(\beta=.51, t=5.54, p<.0001)$, explaining $26 \%$ of the variance of Externalizing problems, Overall $F(1,89)=30.66, p<.0001$. The maltreated children's additional caregiver and nonmaltreated children's mother Benevolence, entered in the second step, were found to be significant $(\beta=-.28, t=-2.98, p<.001$, and to account for an additional $7 \%, F$ change $(2,88)=10.12, p<.001$, of the variance of Externalizing problems, overall $F(2,88)=21.96, p<.0001$. The final model explained $33 \%$ of the variance in Externalizing problems. 
between the caregiver representations at Time 1 and Time 2 and externalizing and internalizing as measured at Time 2. Finally, we explored the direction of the assumed causal associations between maternal and additional caregiver representations and children's symptomatology as reported by the teacher.

\section{Changes over time in the maternal and additional caregiver represen-} tations of maltreated children. To compare maltreated children's representations of their mothers and additional caregivers at Times 1 and 2 , a $2 \times 2$ ANOVA with repeated measures was conducted. The independent repeated measures variables were Time Period (Time 1 and Time 2) and the Type of Figure (mother vs. additional caregiver). The representations' dimensions (Benevolence, Punitiveness, and conceptual level) served as the dependent variables (for means and standard deviations, see Table 2).

After a full Bonferroni correction was applied, results for conceptual level indicated no significant effects for Type of Figure, $F(1,44)=1.24, n s$, or for Time Period, $F(1,44)=3.32, p<.06$. But we did find a significant Type of Figure $\times$ Time Period interaction effect, $F(1,44)=18.75, p<.0001$. Results for Benevolence indicated significant main effects for Time Period, $F(1,44)=8.44, p<.0001$, and for Type of Figure, $F(1,44)=224.74, p<.0001$, as well as a significant Type of Figure $\times$ Time Period interaction, $F(1,44)=33.75, p<.0001$.

Finally, results for Punitiveness indicated significant main effects for Time Period, $F(1,44)=12.89, p<.001$, but not for Type of Figure, $F(1,44)=.79, n s$, as well as a significant Figure $\times$ Time Period interaction, $F(1,44)=16.12, p<.0001$.

Univariate $F$ s indicated that both maternal and additional caregiver representations changed with time. At Time 2, children's representations of their mothers had a higher conceptual level, $F(1,44)$ $=23.77, p<.0001$, and were more Benevolent, $F(1,44)=25.82$, $p<.0001$, and less Punitive, $F(1,44)=19.57, p<.0001$, than their maternal representations at Time 1 . Children's representations of the additional caregiver at Time 2 were significantly less Benevolent than their representations of the additional caregiver at Time 1, $F(1,44)=13.18, p<.0001$. No significant differences were found between Time 1 and Time 2 for the conceptual level or Punitiveness of the representations of the additional caregivers.

Finally, the comparison of maternal and caregiver representations at Time 2 indicated that the additional caregiver representations 
were still more Benevolent, $F(1,44)=28.01, p<.0001$, but also more Punitive, $F(1,44)=7.49, p<.0001$, than the maternal representations. No significant difference in the conceptual level of the representations was noted at Time 2 .

Changes over time in maltreated children's symptomatology. To evaluate changes over time in levels of symptoms, ANOVAs with repeated measures were calculated with Time (Time 1 and Time 2) as the independent repeated measure variable and Externalizing and Internalizing scores as dependent variables. After a full Bonferroni correction was applied, results of the analysis of the Internalizing scores indicated significant effects of Time, $F(1,44)=13.00, p<.0001$, with a significant decline at Time $2, t(1,44)=-2.89, p<.0001(M=16.88$, $S D=1.32$ vs. $M=10.02, S D=1.15$ for Time 1 and Time 2 , respectively). The analysis of the Externalizing scores indicated a significant effect of Time period, $F(1,44)=8.54, p<.0001$, with significant decline at Time 2, $t(1,44)=-2.22, p<.03(M=29.09, S D=2.25$ vs. $M=20.60, S D=2.05$, at Times 1 and 2 , respectively).

Associations between representations' dimensions and symptomatology of maltreated children at Time 2. A full Pearson correlations matrix was calculated between the dimensions of maternal and additional caregiver representations and Externalizing and Internalizing behavior problems among maltreated children at Time 2. Among these correlations, the following associations were the only ones found to be statistically significant.

In contrast to Time 1 , at Time 2 dimensions of representations of mothers and additional caregivers were significantly correlated: Significant positive correlations were found between the conceptual level of the mother and that of the additional caregiver $(r=.35$, $p<.02$ ) and between the maternal Benevolence factor and the additional caregiver representation's Punitiveness factor $(r=.43$, $p<.001)$. However, only a marginal association was found between the Benevolence factor of the maternal representation and that of the additional caregiver representation $(r=-.26, p=.07)$.

In addition, the Benevolence factor of the additional caregiver representations was negatively associated with Externalizing behavioral problems $(r=-.33, p<.05)$, and the Punitiveness factor of the additional caregiver representation was positively correlated with Internalizing behavioral problems $(r=.34, p<.01)$. Moreover, in 
contrast with the observations at Time 1 , at Time 2 significant negative associations were found between the conceptual level scores of the maternal representations and levels of Externalizing and Internalizing behavioral problems $(r=-.41, p<.01$ and $r=-.32$, $p<.05$, respectively). Also at Time 2 , the Punitiveness factor of the maternal representation was positively associated with children's Internalizing problems $(r=.43, p<.01)$. Finally, significant positive correlations were found between Externalizing and Internalizing behavior problems at Time $2(r=.42, p<.001)$.

A crossed-lagged model: The additional caregiver's Benevolence predicts symptomatology. The aim of the following analyses was to explore the direction of the observed effects, as it could be argued that the associations between dimensions of mental representations and symptomology stem from the effects of levels of symptomatology on children's representational dimensions.

We first computed Pearson correlations between symptomatology at Time 2 and the maternal and additional caregiver representations dimensions measured at Time 1 . Analyses revealed that the only significant association between maternal and additional caregiver representations dimensions measured at Time 1 and symptomatology at Time 2 is a negative association between the Benevolence of the additional caregiver representation at Time 1 and the child's Externalizing problems at Time $2(r=-.40, p<.0001)$. To ensure that the association between the additional caregiver's Time 1 Benevolence and the maltreated child's Externalizing symptomatology at Time 2 is robust and not arbitrary, we regressed all of the Time 1 content dimensions on Time 2 Externalizing. Results of the Multiple Regression indicate that Benevolence is still the only predictor of Externalizing at Time 2, beyond other dimensions of Time 1 representations $(\beta=-.38, t=-2.18, p<.04)$. It is important to note here that this effect is still significant when Externalizing behavioral problems at Time 1 were also included in the analysis $(\beta=-.36$, $t=-2.58, p<.02)$. In addition, HMR results did not indicate any significant effect of maternal representations or the interaction between maternal and additional caregiver's representations on the prediction of a child's symptomatology.

We used a crossed-lagged model to explore the causal sequence between the Benevolence of the additional caregiver representation at Time 1 and the children's Externalizing symptomatology at Time 
2. To explore whether the Benevolence of the caregiver representation at Time 1 predicted Externalizing symptoms at Time 2, while assessing measurement errors in the dependent variables and controlling for the association between the Benevolence factor and Externalizing symptoms at both times, two path models were constructed using Structural Equation Modeling (Hoyle \& Smith, 1994). Using Amos 4.0 software based on the variance-covariance matrix (Aurbackle, 1994), we tested the fit of these models using maximum likelihood estimations.

In the following models, both Externalizing symptoms and the Benevolence of the additional caregiver representation at Time 1 were the predictors and Externalizing symptoms and the additional caregiver Benevolence at Time 2 were the criteria. In addition, we controlled for the association between Externalizing symptoms and the Benevolence factor of the additional caregiver representation at Time 1 and for their shared measurement error terms at Time 2 (see Figure 1).

We first examined the full model, delineating the direct effects (i.e., the effect of the Benevolence of the additional caregiver's representation at Time 1 on the Benevolence of the additional caregiver's representation at Time 2 and the effect of Externalizing symptoms at Time 1 on Externalizing symptoms at Time 2) and the cross effects (the effects of the Benevolence factor at Time 1 on the Externalizing Symptoms at Time 2 and the effects of the Externalizing Symptoms at Time 1 on the Benevolence factor at Time 2) and controlling for the predictors' associations and outcome error terms (see Figure 1).

The full model showed a nonsignificant effect of Time 1 Benevolence on Time 2 Benevolence $(\beta=-.06, t=-.42, n s)$, whereas Time 1 Benevolence was found to have a significant effect on Externalizing symptoms at Time $2(\beta=-.41, t=-3.01, p<.001)$. The effect of Externalizing symptoms at Time 1 on Externalizing symptoms at Time 2 was also significant $(\beta=.39, t=2.87, p<.001)$, but the effect of Externalizing symptoms at Time 1 on the Benevolence factor at Time 2 was not significant $(\beta=-.08, t=-.56, n s)$. This model significantly explained $0 \%$ and $33 \%$ of the variance in the additional caregiver's Benevolence factor and of children's Externalizing symptoms, respectively, at Time 2 (see Figure 1). However, this model had zero degrees of freedom, so fit could not be estimated. 
To obtain the most parsimonious model and allow the evaluation of the overall goodness of fit of the path model, we calculated a final model in which we removed the nonsignificant paths found in the full model. In this final model, we delineated the effect of the Externalizing symptoms at Time 1 on the Externalizing symptoms at Time 2 and the effect of the Benevolence factor at Time 1 on Externalizing Symptoms at Time 2 while controlling for the predictors' associations and outcome error terms. This model had acceptable indices of fit:

RMSEA $=.000$;

$$
\begin{aligned}
\chi^{2}[2, N & =45]=.50 ; \chi^{2} / d f=.25 ; p=.78 . ; G F I=.99 ; \\
A G F I & =.97 ; C F I=1.00 .
\end{aligned}
$$

These findings indicate with considerable certainty that the Benevolence of the additional caregiver representation at Time 1 predicts or affects children's Externalizing symptoms at Time 2 and that the Externalizing symptoms at Time 1 do not predict or affect the Benevolence of the additional caregiver representation at Time 2.

Summary of the findings of the longitudinal study. The main findings of the longitudinal study of the maltreated children were as follows.

1. Both maternal and additional caregiver representations changed over time. At Time 2, children's representations of their mothers had a higher conceptual level and were more benevolent and less punitive than their maternal representation at Time 1. Children's representations of their additional caregivers at Time 2 were significantly less Benevolent than their representations of the additional caregiver at Time 1 . We found no significant differences between the conceptual levels of the representations at Times 1 and 2 or between the Punitiveness scores of the representations of the additional caregiver at Times 1 and 2. Comparisons between maternal and caregiver representations at Time 2 indicated that the representations of the additional caregiver were still more Benevolent but also more Punitive than the representations of the mother. There were no significant differences in conceptual level scores.

2. We found significant positive correlations between the conceptual level of the representations of the mother and the additional caregiver and between the maternal Benevolence factor and the additional caregiver Punitiveness factor at Time 2. In 
addition, a marginal association was found between the Benevolence of the representations of the mother and that of the caregiver representations.

3. Over time, significant declines in both Externalizing and Internalizing scores were observed.

4. The Benevolence of the representation of the additional caregiver (but not of the mother) at Time 1 predicted maltreated children's Externalizing symptoms at Time 2, beyond Time 1 symptomatology.

\section{DISCUSSION}

The present study focused on the exploration of characteristics of maternal and additional caregiver representations among maltreated children in long-term residential care as well as the continuity of these characteristics over time and their effects on children's symptomatology. Our findings indicate the plausibility of the construction of a new, more benign additional caregiver representation among school-age children who have suffered severe maltreatment and been subsequently placed in long-term residential care as well as the plausibility of changes in the maternal representations. These changes were accompanied by a significant reduction in children's overall symptomatology. Moreover, the Benevolence of the additional caregiver representations was found to predict maltreated children's levels of Externalizing symptom after 30 months, beyond the effect of the Externalizing symptoms present at the time of the first measurement.

\section{Maltreated Children's Maternal and Additional Caregiver Representations}

After 18 months in long-term residential care, maltreated children's maternal representations were found to be less cognitively complex, less benevolent, and more punitive than their representations of their additional caregivers. Given the similarity of assessment procedures, the differences between maternal and additional caregiver representations at Time 1 are rather conspicuous. These differences may reflect children's real experiences with each caregiver as well as their need to maintain a clear differentiation between these two relationships, thus accommodating to the difficulties they face in dwelling far from home in a very different environment. The additional caregiver's marked benevolence may reflect a positive 
interpersonal relationship with the additional caregiver in reality as well as the child's capacity to construe, after a year an a half, a new, more benign caregiver representation. The higher conceptual level that accompanies the positive content of the representations of the additional caregiver (as compared to the maternal representations) may reinforce this optimistic interpretation. However, positive representations of the additional caregiver can also be seen as effects of defensive processes that have been well documented among maltreated children. For instance, the effect of the idealization of parents among maltreated children has been previously noted by several researchers (see, e.g., Bretherton \& Munholland, 1999; Oppenheim, Emde, \& Warren, 1997; Toth et al., 1997). This idealization may be related to the children's need to protect these caregivers by overstating their benevolence and/or an adaptive cognitive style (Ackerman \& Dozier, 2005; Dozier et al., 2002).

The marked positivity that characterized the narratives of the additional caregiver at Time 1 can be seen as special case of the segregation (Bowlby, 1980) of negative emotions, mainly anger, from the child's attachment to the caregiver, anger that might otherwise alienate the attachment figure. According to Bowlby (1980), the result of this segregation is that behavior, feeling, and thoughts become disconnected from each other. Further analyses of real-life interactions taking place between maltreated children and their additional caregivers would help us to understand the positive representations. In any case, the observed maturation of the representations over time (increase in conceptual level), including those of the biological mother, may suggest an important development in the ability to mentalize, that is, to envision one's own mental states (feelings, beliefs, intentions, and desires) and those of others, and to consider mental states in attempts to understand why people behave as they do (Fonagy \& Target, 1997). The negative associations observed between the additional caregiver's Benevolence and the child's maladaptive behavior might further support the interpretation of our findings as resulting from a process of maturation and the development of the ability to mentalize in this sample.

On the methodological level, the marked Benevolence of the additional caregivers could be seen as reflecting children's reticence to speak negatively about their caregivers due to fears of retaliation or abandonment. Although this argument cannot be dismissed in the case of maltreated children, we would like to note here that the 
interview procedure was thoroughly designed to create positive rapport, anonymity was assured, and the results obtained have a sound theoretical end empirical background. In addition, it is important to note that at Time 2, when we used the same procedure, the idealization of the additional caregiver was found to be diminished.

Previous research has documented the importance of the length of the period of time the child has spent with an additional caregiver when predicting change (Howes, 1999). Indeed, 30 months after our first assessment, we did find changes in both maternal and caregiver representations. Whereas maternal representations became more mature and less negative, the additional caregiver representations became less benevolent over time. In addition, the conceptual level of the representations was similar and correlated. This pattern of findings might suggest that the lower level of symptomatology registered at Time 2 was accompanied by representations that were less dissociated from each other (Berlin \& Cassidy, 1999; Bretherton, 1985). Less negative maternal representations might result from the lack of continuous everyday contact with the mother, but in any case the somewhat more integrated system of representations found among maltreated children at Time 2 provides additional evidence of the effects of one secure attachment on children's behavior as well as on their representations.

\section{Content of Representations and Children's Symptomatology}

Higher levels of Externalizing behaviors have been found to characterize children living out of their homes (Dozier et al., 2002). In the present study, higher levels of Externalizing symptoms were found to be associated with less benevolent representations of the additional caregiver at both times of measurements, confirming previous research's emphasis on the association between positive representations of caregivers and impulse control (Fonagy et al., 1995; Priel et al., 1995; Sroufe, 1996).

Whereas the Benevolence of the additional caregiver was associated with children's levels of Externalizing problems as assessed by the teacher, maternal representation dimensions were not correlated with children's symptoms. This unexpected finding might suggest that the children's representations of their current main caregiver predict adjustment, whereas other representations change with time and circumstances and may be related to other, less overt 
aspects of the children's development. This last possibility merits further investigation.

It is important to note here the lack of findings on specific effects of subtypes or time of onset of maltreatment. This lack of findings may reflect the overall severity of the maltreatment that the children in our sample had suffered, maltreatment severe enough to result in court-ordered removal from their homes and placement in long-term residential care. This might have created a ceiling effect that covered possible differences.

The findings that lower associations appear between dimensions of representations of both mother and additional caregiver and Internalizing symptoms may be attributed to the fact that data on symptoms was collected from the children's teachers, who may be more acquainted with children's Externalizing behaviors than with their Internalizing behaviors.

\section{The Prediction of Externalizing Symptomatology}

Findings concerning the associations between the additional caregiver's Benevolence and Externalizing symptoms were corroborated longitudinally. The analysis of causal patterns shows the predictive power of the Benevolence of the additional caregiver representations, beyond the levels of symptomatology measured at Time 1 . These findings are based on a fairly conservative analysis using a design that is longitudinal and based on different sources for the assessment of the independent and the dependent variables. These findings turn us back to the problem of the conspicuous Benevolence scores of additional caregivers' representations 18 to 21 months after children had entered into the foster homes. These findings underscore the positive effects of the Benevolence of the representation, be it a reflection of the real quality of caregiver-child relationships or a defensive strategy to ensure continuity of care. Perhaps these are not always competing explanations but are different aspects of the complexity of the interactions involved in maltreated children's ways of coping with new, different care-giving relationships.

Findings concerning the positive effects of the additional caregiver representations are congruent with previous findings on the associations between positive representations of therapists and outcomes of psychotherapy (Blatt, Auerbach, \& Levy, 1997). However, the causal link found between the additional caregiver Benevolence and 
children's Externalizing symptoms does not eliminate the possible effects of additional variables, such as impulsiveness, that could affect children's narratives as well as teachers' reports. Further research should include additional mediating or moderating variables that may affect the association between representations' dimensions and children's behavior.

\section{Study Limitations}

Despite the strengths of our study, at least three caveats should guide the interpretation of these findings. First, the interpretation of our findings is limited by the confounding between the effects of maltreatment and those of being away from home (Dozier et al., 2002). Further research is needed to disentangle these related but different sources of effects on children's adjustment, and preplacement data collection may be very helpful in clearing up this confounding. The longitudinal study of an additional sample of maltreated children living with their birth parents may provide a partial answer to this question, but it should be taken into account that children who have been placed in long-term residential care as a result of maltreatment constitute, by definition, a special population growing up in more severely adverse circumstances than most other maltreated children.

Second, another limitation to the generalizability of our findings might be the lack of IQ assessments, even though all the children were attending regular schools and important deviations for normal IQ are highly improbable. Even though the use of children's verbal fluency as a covariate in between-groups' analyses reduces the magnitude of this omission, detailed information about children's specific intellectual capabilities might be relevant, mainly as a resilience factor.

Third, no sexual abuse was reported for our sample. It is important to include this variable in further research.

Fourth, our findings, although centered on assessments of representations of caregivers, reflected a specific aspect of an extensive environmental change that needs further broad investigation. This process might include the evolving relationships with new peers, the effects of the changes that took place in the school environment, the quality of the relationships the children keep with their parents, and so forth. All of these factors (and plausibly many more) might affect children's adjustment, together with the aspects of internal representations reported here. In addition, future studies should include 
also evaluations of children's self-representations, because changing representations of self in addition to representations of others might affect children's adjustment.

Finally, the design utilized did not include a second wave of measurement of nonmaltreated children that could have added relevant information, and nonmaltreated children were asked to provide one narrative (mother) whereas maltreated children were asked to tell about their mother and additional caregiver. Even though the order of narratives was controlled for and, in reality, only the maltreated children had an additional caregiver, future research may improve on this design by asking both samples to provide the same number of narratives.

In summary, the pattern of findings obtained corroborates evidence from extant literature on the importance of at least one positive caregiver representation for children's self-regulation of behavior and suggests the dynamic nature of all existing representations. This study allowed us to look "from the inside out" (Brinich, 1990) at the ways in which aspects of internal representations affect the development and psychopathology of maltreated children. Our findings show positive changes over time in children's maternal representations and behavior, as well as the development of more realistic additional caregiver representations. Maltreated children living out of their homes seem to be able, over time, to overcome, at least in part, their basic negative representations of early caregiving relationships. However, although new relationship patterns may play a prominent role in defining children's actual adjustment, all their relationship representations seem to continue to develop and play crucial but as-of-yet unclear roles in their development.

\section{REFERENCES}

Achenbach, T. M. (1991). Manual for the teacher's report form and 1991 profile. Burlington, VT: University of Vermont, Department of Psychiatry.

Ackerman, J. P., \& Dozier, M. (2005). The influence of foster parent investment on children's representations of self and attachment figures. Applied Developmental Psychology, 23, 507-520.

American Psychiatric Association (1994). Diagnostic and statistical manual of mental disorders (4th ed). Washington, DC: Author.

Aurbackle, J. L. (1994). AMOS: A structural equation modeling program. Chicago: SmallWaters. 
Avery, R. R., \& Ryan, R. M. (1988). Object relations and ego development: Comparison and correlates in middle childhood. Journal of Personality, 56, 547-569.

Baldwin, M. W. (1992). Relational schemas and the processing of social information. Psychological Bulletin, 112, 461-484.

Barnett, D., Manly, J. T., \& Cicchetti, D. (1993). Defining child maltreatment: The interface between policy and research. In D. Cicchetti \& S. L. Toth (Eds.), Child abuse, child development, and social policy (pp. 7-74). Norwood, NJ: Ablex.

Besser, A., \& Blatt, S. J. (2007). Identity consolidation and internalizing and externalizing problem behaviors in early adolescence. Psychoanalytic Psychology, 24, 126-149.

Berlin, L. J., \& Cassidy, J. (1999). Relations among relationships. In J. Cassidy \& P. R. Shaver (Eds.), Handbook of attachment theory, research and clinical application (pp. 688-712). New York: The Guilford Press.

Blatt, S. J. (1995). Representational structures in psychopathology. In D. Cicchetti \& S. L. Toth (Eds.), Rochester symposium on developmental psychopathology: Emotion, cognition, representation (vol. 6, pp. 1-33). Rochester, NY: University of Rochester Press.

Blatt, S. J., Auerbach, J. S., \& Levy, K. N. (1997). Mental representations in personality development, psychopathology, and the therapeutic process. Review of General Psychology, 1, 351-374.

Blatt, S. J., Chevron, E. S., Quinlan, D. M., Schaffer, C. E., \& Wein, S. (1992). The assessment of qualitative and structural dimensions of object representations (rev. ed.). Unpublished manual. New Haven, CT: Yale University.

Blatt, S. J., \& Lerner, H. L. (1983). The psychological assessment of object representations. Journal of Personality Assessment, 59, 82-98.

Blatt, S. J., Wiseman, H., Prince-Gibson, E., \& Gatt, C. (1991). Object representation and change in clinical functioning. Psychotherapy: Research, Theory \& Practice, 28, 273-283.

Bowlby, J. (1969). Attachment and loss: Attachment. New York: Basic Books.

Bowlby, J. (1973). Attachment and loss: Separation, anxiety and anger. New York: Basic Books.

Bowlby, J. (1980). Attachment and loss: Loss. New York: Basic Books.

Bretherton, I. (1985). Attachment theory, retrospect and prospect. Monographs of the Society of Research in Child Development, 50 (1-2, serial No 209), 3-35.

Bretherton, I., \& Munholland, K. A. (1999). Internal working models in attachment relationships: A construct revisited. In J. Cassidy \& P. R. Shaver (Eds.), Handbook of attachment theory, research and clinical applications (pp. 89-114). New York: The Guilford Press.

Brinich, P. M. (1990). Adoption from inside out: A psychoanalytic perspective, In D. Bruner, J. S. (1964). The course of cognitive growth. American Psychologist, 19, $1-15$.

Bruner, J. S. (1964). The course of cognitive growth. American Psychologist, 19, 115.

Chapman, M. V., Wall, A., \& Barth, R. P. (2004). Children's voices: The perceptions of children in foster care. American Journal of Orthopsychiatry, 74, 293-304. 
Cicchetti, D., \& Rizley, R. (1981). Developmental perspectives on the etiology, intergenerational transmission, and squeal of child maltreatment. New Direction for Child Development, 11, 31-55.

Cicchetti, D., \& Toth, S. L. (2002). Developmental processes in maltreated children. Nebraska Symposium on Motivation, 46, 85-130.

Davidson-Arad, B. (2005). Fifteen-month follow up of children at risk: Comparison of the quality of life of children removed from their home and children remaining at home. Children and Youth Services Review, 27, 1-20.

Diamond, G. M., Didner, H., Waniel, A., Priel, B., Asherov, J., \& Arbel, S. (2005). Perceived parental care and control among Israeli female adolescents presenting to emergency rooms after self-poisoning. Adolescence, 40, 257-272.

Dozier, M., Albus, K., Fisher, P. A., \& Sepulveda, S. (2002). Intervention for foster parents: Implications for developmental theory. Development and Psychopathology, 14, 843-860.

Egeland, B., Jacobovitz, D., \& Sroufe, L. A. (1988). Breaking the cycle of abuse: Relationship predictions. Child Development, 59, 1080-1088.

Fonagy, P., Steele, M., Steele, H., Leigh, T., Kennedy, R., \& Mattoon, G., et al. (1995). Attachment, the reflective self, and borderline states. In S. Goldberg, R. Muir, \& J. Kerr (Eds.), Attachment theory: Social, developmental and clinical perspectives (pp. 233-278). Hillsdale, NJ: The Analytic Press.

Fonagy, P., \& Target, M. (1997). Attachment and reflective function: Their role in self organization. Development and Psychopathology, 9, 679-700.

Greenberg, M. T. (1999). Attachment and psychopathology in childhood. In J. Cassidy \& P. R. Shaver (Eds.), Handbook of attachment: Theory, research and clinical applications (pp. 671-686). New York: The Guilford Press. (pp. 469-496).

Hesse, E. (1999). The Adult Attachment Interview: Historical and current perspectives. In J. Cassidy \& P. R. Shaver (Eds.), Handbook of attachment: Theory, research, \& clinical applications (pp. 395-433). New York: The Guilford Press.

Horowitz, M. J. (1972). Modes of representation of thought. Journal of the American Psychoanalytic Association, 20, 793-819.

Howes, C. (1999). Attachment relationships in the context of multiple caregivers. In J. Cassidy \& P. R. Shaver (Eds.), Handbook of attachment: Theory, research and clinical applications (pp. 671-686). New York: The Guilford Press.

Howes, C., \& Segal, J. (1993). Children's relationships with alternative caregivers: The special case of maltreated children removed from their homes. Journal of Applied Developmental Psychology, 14, 71-81.

Hoyle, R. H., \& Smith, G. (1994). Formulating clinical research hypotheses as structural equation models: A conceptual overview. Journal of Consulting and Clinical Psychology, 62, 429-440.

Lynch, M., \& Cicchetti, D. (1991). Patterns of relatedness in maltreated and nonmaltreated children: Connections among multiple representational models. Development and Psychopathology, 3, 207-226.

Macfie, J., Toth, S. L., Rogosch, F. A., Robinson, J. A., Emde, R.N, \& Cicchetti, D. (1999). Effect of maltreatment on preschoolers narrative representations of responses to relieve distress and of role reversal. Developmental Psychology, 35, 460-465. 
Main, M., Kaplan, N., \& Cassidy, J. (1985). Security in infancy, childhood and adulthood: A move to the level of representation. In I. Bretherton \& E. Waters (Eds.), Growing points in attachment: Theory and research. Monographs of the Society for Research in Child Development, Serial 209 (pp. 66-104). Chicago, IL: University of Chicago Press.

Manly, J. T., Kim, J. E., Rogosch, F. A., \& Cicchetti, D. (2001). Dimensions of child maltreatment and children's adjustment: Contributions of developmental timing and subtype. Development and Psychopathology, 13, 759-782.

McCrone, E. R., Egeland, B., Kalkoske, M., \& Carlson, E. A. (1994). Relations between early maltreatment and mental representations of relationships assessed with projective storytelling in middle childhood. Development and Psychopathology, 6, 99-120.

Milan, S. E., \& Pinderhughes, E. E. (2000). Factors influencing maltreated children's early adjustment in foster care. Development and Psychopathology, 12, 63-81.

Oppenheim, D., Emde, R. N., \& Warren, S. (1997). Children's narrative representations of mother: Their development and association with child and mother adaptation. Child Developmental, 68, 127-138.

Piaget, J. (1955). The language and thought of the child. New York: Hartcourt Brace.

Piaget, J. (1962). Play, dreams, and imitation in childhood. New York: Norton.

Priel, B. (2005). Representations in middle childhood: A dialogical perspective. In J. S. Auerbach, K. N. Levy, \& C. E. Schaffer (Eds.), Relatedness, self-definition, and mental representation: Essays in honor of Sidney J. Blatt (pp. 43-57). New York: Bruner and Routlege.

Priel, B., Kantor, B., \& Besser, A. (2000). Two maternal representations: A study of Israeli adopted children. Psychoanalytic Psychology, 17, 128-145.

Priel, B., Myodovnick, E., \& Rivlin-Beniaminy, N. (1995). Parental representations among preschool and fourth-grade children: Integrating object relational and cognitive developmental frameworks. Journal of Personality Assessment, 65, 372-388.

Priel, B., Seksig-Bitton, I., Waniel, A., Myodovnick, E., \& Rosen, G. (2002). The assessment of object representations: A rating manual of children's parental descriptions (ages 6 to 13 years). Unpublished manual. Beer-Sheva, Israel: BenGurion University of the Negev.

Rosenfield, A., Pilowsky, D., Fine, P., Thorpe, M., Fein, E., \& Simms, M., et al. (1997). Foster care: An update. Journal of the American Academy of Child and Adolescent Psychiatry, 36, 448-457.

Rutter, M. (1989). Intergenerational continuities and discontinuities. In D. Cicchetti \& V. Carlson (Eds.), Child maltreatment: Theory and research on the causes and consequences of child abuse and neglect (pp. 300-330). New York: Cambridge University Press.

Sameroff, A. J. (1995). General systems theories and developmental psychopathology. In D. Cicchetti \& D. J. Cohen (Eds.), Developmental psychopathology (pp. 659-695). New York: Wiley.

Sandler, J., \& Rosenblatt, B. (1962). The concept of the representational world. The Psychoanalytic Study of the Child, 17, 128-145. 
Segal, H. G., Westen, D., Lohr, N.E, Silk, K. R., \& Cohen, R. (1992). Assessing object relations and social cognition in borderline personality disorders from stories told to the Picture Arrangement subtest of the WAIS-R. Journal of Personality Disorders, 6, 458-470.

Shields, A. M., Ryan, R. M., \& Cicchetti, D. (2001). Narrative representations of caregivers and emotional dysregulation as predictors of maltreated children's rejection by peers. Developmental Psychology, 37, 321-337.

Shrout, P. E., \& Fleiss, J. L. (1979). Intraclass correlations: Uses in assessing rater reliability. Psychological Bulletin, 86, 420-428.

Sroufe, L. (1996). Emotional development: The organization of emotional life in the early years. New York: Cambridge University Press.

Sroufe, L., Carlson, E. A., Levy, A. K., \& Egeland, B. (1999). Implications of attachment theory for developmental psychopathology. Development and Psychopathology, 11, 1-13.

Thompson, R. A. (2000). The legacy of early attachments. Child Development, 71, $145-152$.

Toth, S. L., \& Cicchetti, D. (1996). The impact of relatedness with mother on school functioning in maltreated youngsters. Journal of School Psychology, 3, 247-266.

Toth, S. L., Cicchetti, D., \& Kim, J. (2002). Relations among children's perceptions of maternal behavior, attributional styles, and behavioral symptomatology in maltreated children. Journal of Abnormal Child Psychology, 30, 487501.

Toth, S. L., Cicchetti, D., Macfie, J., \& Emde, R. N. (1997). Representations of self and other in the narratives of neglected, physically abused, and sexually abused preschoolers. Development and Psychopathology, 9, 781-796.

Toth, S. L., Cicchetti, D., Macfie, J., Maughan, A., \& Vanmeenen, K. (2000). Narrative representations of caregivers and self in maltreated pre-schoolers. Attachment and Human Development, 2, 271-305.

Waniel, A., Besser, A., \& Priel, B. (2006). Representations of self and mother in middle childhood: Associations between internal representations and observed adjustment. Journal of Personality, 74, 223-265.

Weinfield, N. S., Sroufe, L. A., \& Egeland, B. (2000). Attachment from infancy to adulthood in a high-risk sample: Continuity, discontinuity and their correlates. Child Development, 71, 695-702.

Weinfield, N. S., Whaley, G. J. L., \& Egeland, B. (2004). Continuity, discontinuity, and coherence in attachment from infancy to late adolescence: Sequelae of organization and disorganization. Attachment and Human Development, 6, 73-97.

Werner, E. E. (2000). Protective factors and individual resilience. In J. P. Shonkoff \& J. P. Meisels (Eds.), Handbook of early childhood intervention (pp. 115132). New York: Cambridge University Press.

Werner, H. (1948). Comparative psychology of mental development. New York: International University Press.

Werner, H., \& Kaplan, B. (1963). Symbol formation: An organismic-developmental approach to language and the expression of thought. New York: Wiley.

Westen, D. (1991). Clinical assessment of object relations using the TAT. Journal of Personality Assessment, 56, 56-74. 


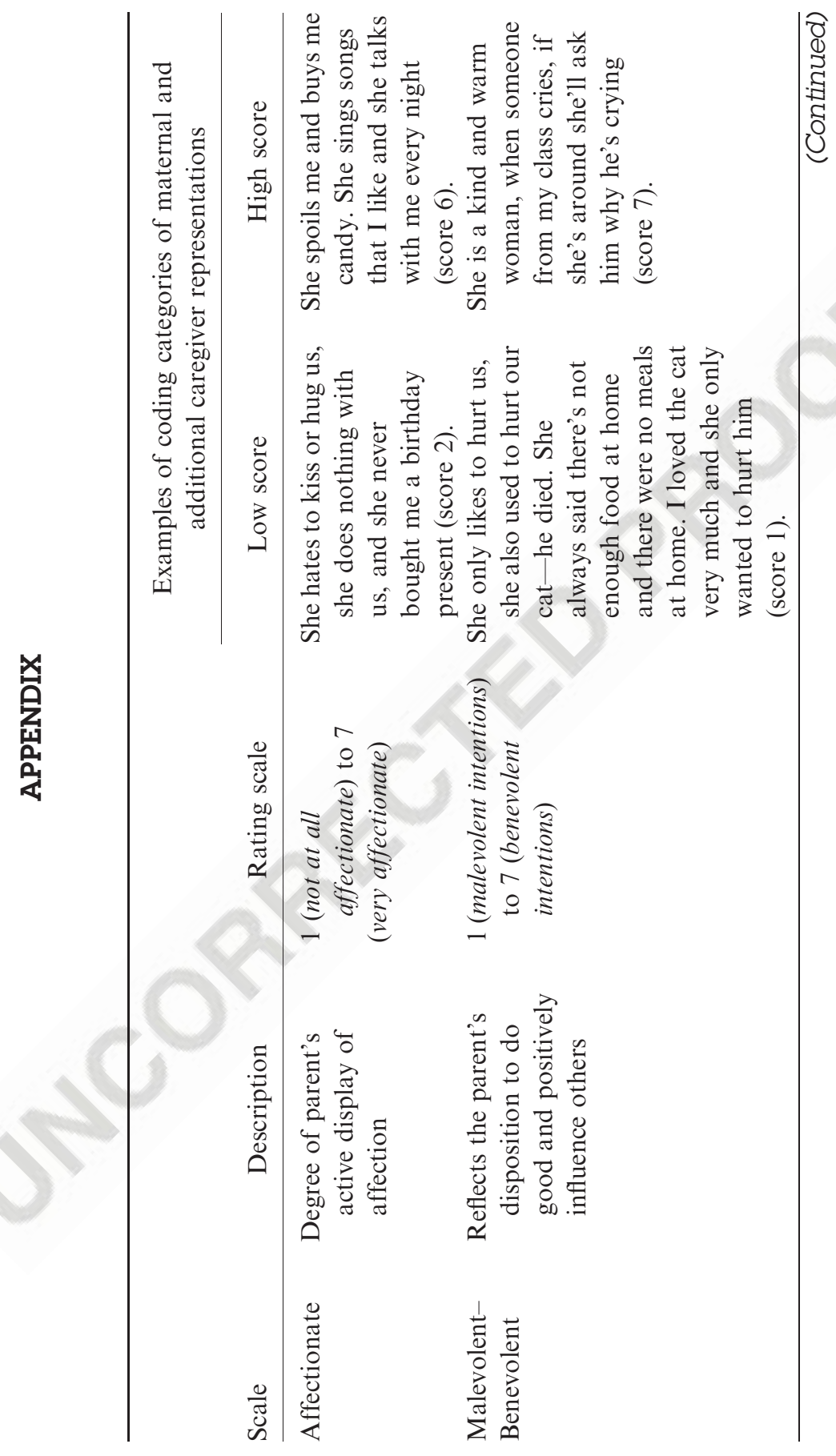

22 


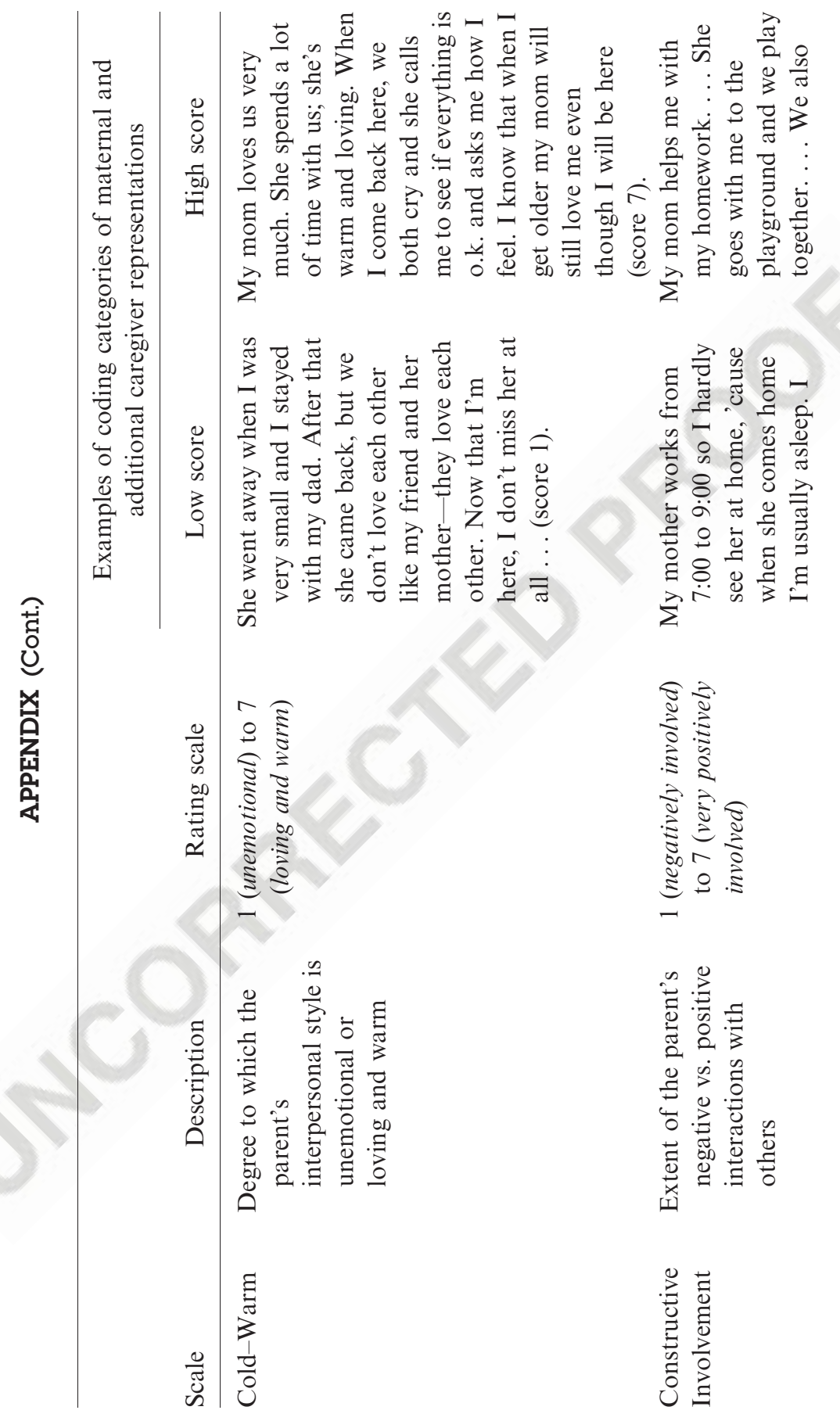



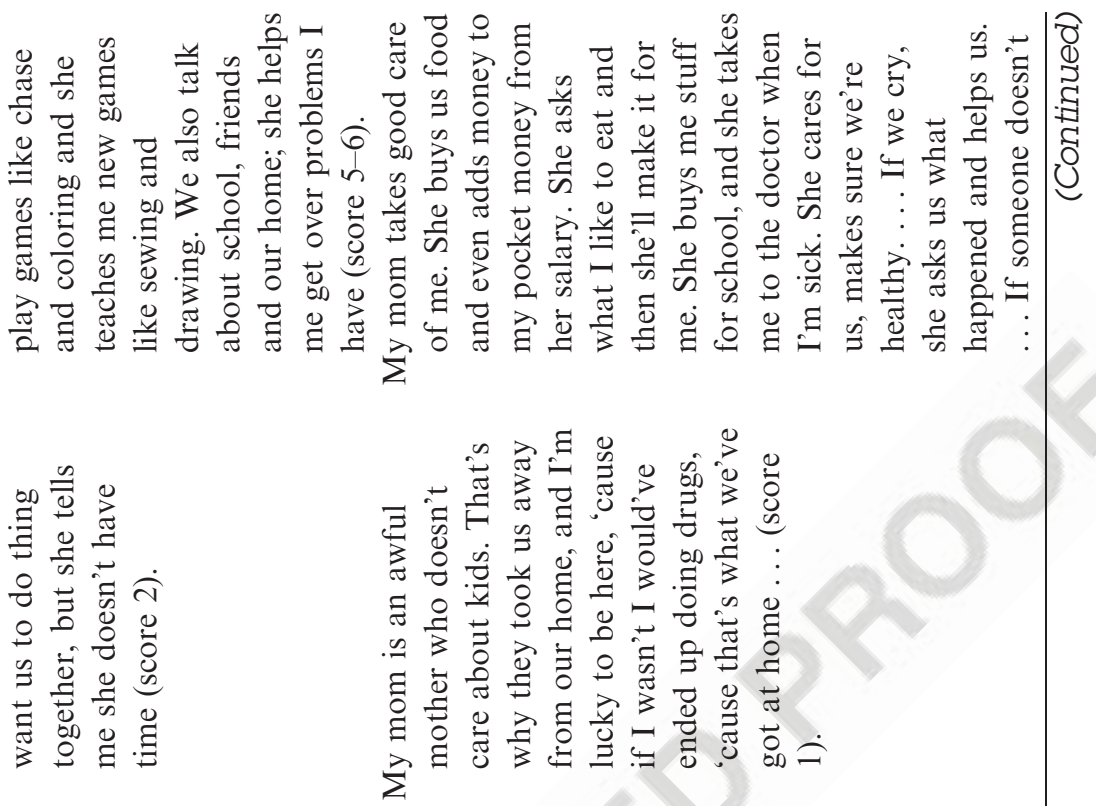

18

20

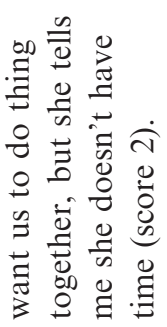

27

종 8

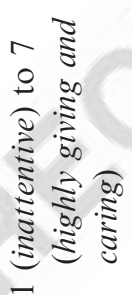

0
0
0
0
0
0
0

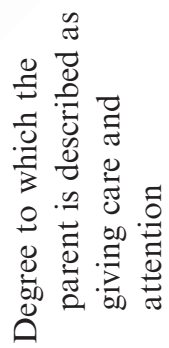




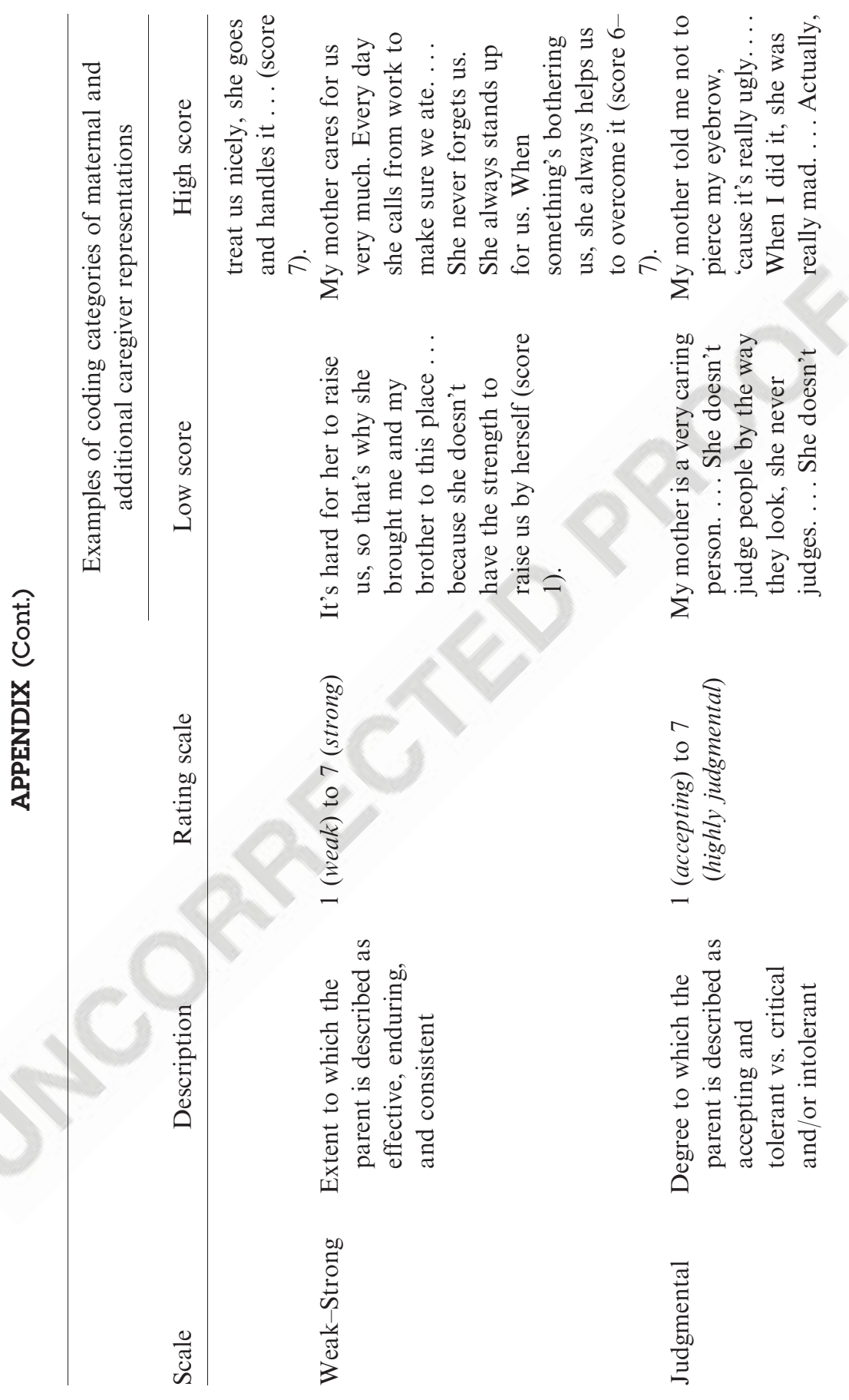

\&్c0 


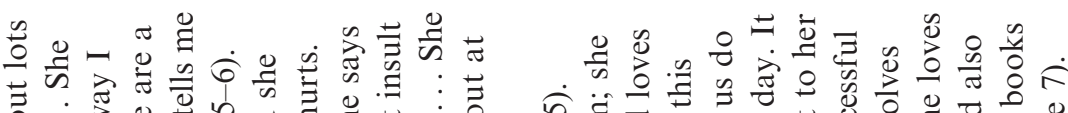

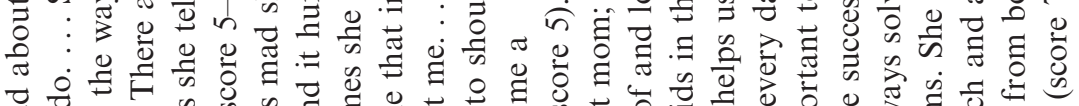

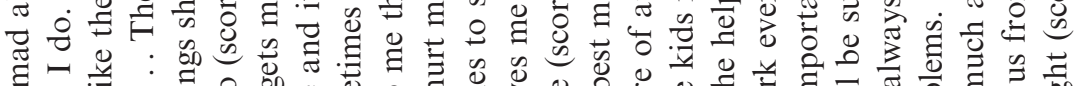

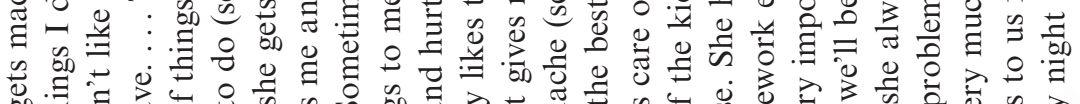

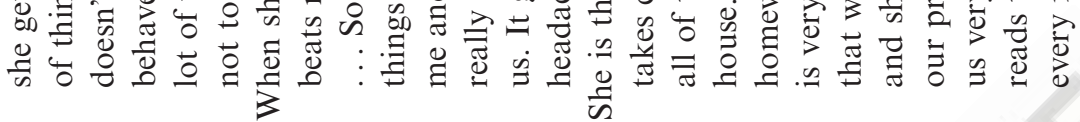

$\Xi \stackrel{\Xi}{\Xi}$

تृ

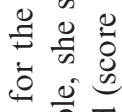

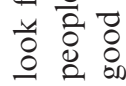

17

18

19

20

21

22

23

24

25

26

27

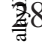

营9

30

妾 1

3्रे

递 3

34

35

क्षे

สี่7

उ్ำ

अ 9

ğ్̣0

竞

о

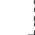

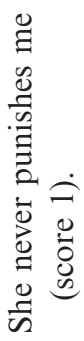

区 过
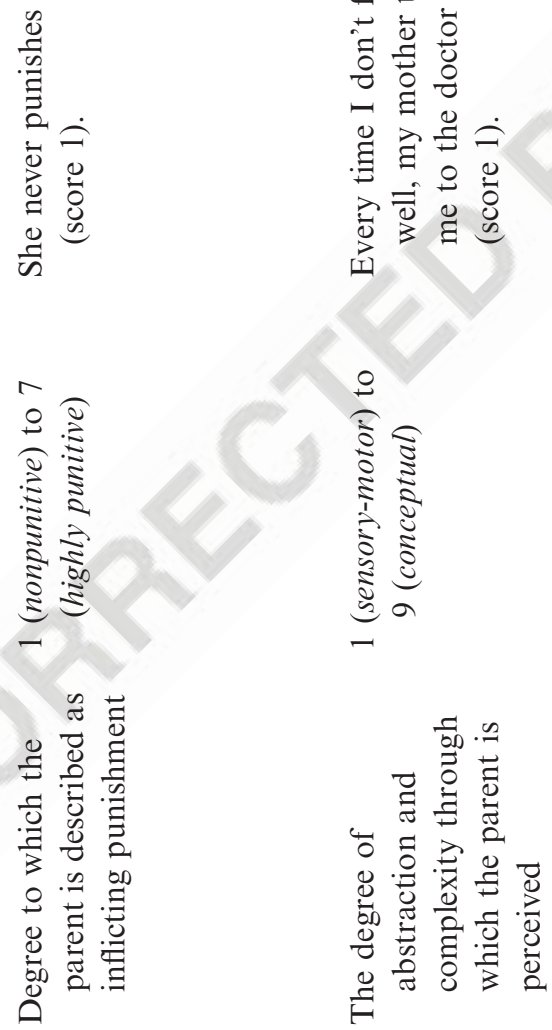

ב

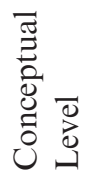

